\title{
Application of an anionic polymer in the formulation of floating tablets containing an alkaline model drug
}

\author{
Dorota Wójcik-Pastuszka ${ }^{1, B-F}$, Iwona Golonka ${ }^{1, B-D}$, Andrzej Drys ${ }^{1, C, D}$, Jobst B. Mielck ${ }^{2, E, F}$, Maria Twarda ${ }^{1, B, D}$, Witold Musiał , A-F \\ ${ }^{1}$ Department of Physical Chemistry, Wroclaw Medical University, Poland \\ ${ }^{2}$ Institut für Pharmazie, Abteilung Pharmazeutische Technologie, Hamburg, Germany \\ A - research concept and design; $B$ - collection and/or assembly of data; $C$ - data analysis and interpretation; \\ $D$ - writing the article; $E$ - critical revision of the article; $F$ - final approval of the article
}

\author{
Address for correspondence \\ Witold Musiał \\ E-mail: witold.musia@@umed.wroc.pl \\ Funding sources \\ None declared \\ Conflict of interest \\ None declared

\section{Acknowledgments} \\ This research was partially performed within \\ the scope of project No. ST-847 of the Wroclaw \\ Medical University, Poland. Electron microscopy \\ microphotographs were performed at the Uni- \\ versity of Hamburg, Germany.
}

Received on February 25, 2016

Reviewed on July 13,2016

Accepted on September 30, 2016

\begin{abstract}
Background. Gastric residence time is the key factor affecting the bioavailability of active pharmaceutical ingredients absorbed mainly through the gastric mucous membrane and influencing the local activity of some drugs.
\end{abstract}

Objectives. The aim of this study was the development of a new composition of non-effervescent floating tablets and the evaluation of the effect of an anionic polymer and compressive force on the floating properties and release characteristics of tablets containing a model alkaline drug, chlorhexidine (CHX).

Material and methods. Direct compression was applied to a polyacrylic acid derivative and sorbitol to fabricate the tablets. Drug release was analyzed using several kinetic models. The formulations floated on the surface of the fluid for $24 \mathrm{~h}$. The values of the rate constants, statistical parameters, and half-release time $\left(\mathrm{t}_{0.5}\right)$ were calculated.

Results. The diffusion coefficient $n$ falls between $0.54 \pm 0.02$ and $0.81 \pm 0.03$ for most formulations. The floating time (FT) and floating lag time (FLT) were found to depend on the amount of polymer incorporated in the formulations. A high compressive force sustained the release of the drug but reduced the FT and FLT. Based on the $\mathrm{FT}$ and $\mathrm{t}_{0.5}$, it was determined that the $\mathrm{C} 1$ composition is the optimal formulation with FT $>24 \mathrm{~h}$ and $\mathrm{t}_{0.5}$ between $113 \pm 2$ and $144 \pm 13$ min, depending on the drug release model.

Conclusions. The application of an anionic polymer results in a prolonged release of the drug from the tablets and allows them to float on fluid surfaces.

Key words: chlorhexidine, carbopol, floatation, kinetics of drug release

DOI

$10.17219 /$ acem/65507

Copyright

Copyright by Author(s)

This is an article distributed under the terms of the

Creative Commons Attribution Non-Commercial License

(http://creativecommons.org/licenses/by-nc-nd/4.0/) 


\section{Introduction}

Oral delivery is a simple, convenient and patient-friendly route for drug delivery. There are many factors affecting the bioavailability of orally administered drugs. Numerous active pharmaceutical ingredients (APIs) are absorbed in only specific regions of the gastrointestinal tract (GIT). Thus, gastric residence time (GRT) is a factor affecting the bioavailability of APIs absorbed through the gastric mucous membrane, as well as through further parts of the GIT. ${ }^{1}$ Several systems have been developed to prolong the retention time of drug dosage in the stomach, including bioadhesive, swellable, or floating systems. Floating methods seem to be promising in controlling gastroretention, ensuring that the level of drug concentration in the plasma remains therapeutically effective over a longer period. ${ }^{2}$ Diet and complex gastric motility play an important role in gastric retention behavior. ${ }^{3-6}$ Several studies have been conducted on the formulations of effervescent tablets and non-effervescent tablets with prolonged GRTs. ${ }^{7-15}$ Floating effervescent tablets contain sodium bicarbonate and citric acid that enable floatage of the tablet on the surface of the gastric fluid by releasing carbon dioxide upon contact with water in the GIT. Consequently, the density of the tablet decreases, resulting in floatation. However, the device may rapidly exit the stomach prior to becoming buoyant as the system does not float immediately after administration. ${ }^{16}$ Non-effervescent systems do not produce carbon dioxide and remain buoyant, even after 24 h. ${ }^{11,14,15}$ Their floating capabilities are due to a specific combination of polymers, which include gel forming hydrocolloid polymers, viz polycarbonates and polystyrenes, as well as bioadhesive polymers, such as chitosan. There are several types of floating systems: single layer and bilayer tablets, alginate beads or hollow microspheres, e.g., micro-balloons. Single layer tablets are formulated by mixing the drug with the gel-forming hydrocolloid. After oral administration of such a dosage form, the tablet swells upon contact with the gastric fluid and attains a decreased volume density. Floatation results from air trapped in the expanding gel structure. The gel serves as a reservoir and controls the drug release from the hydrogel matrix..$^{12,13}$

Sauzet et al. investigated single layer polymer tablets composed of theophylline as a model drug, silicon dioxide as a hydrophobic dusty powder, polyvinyl pyrollidone K30 as a binder, and stearic acid as a controlled release agent. ${ }^{11}$ Such a constitution and porous structure in the tablets ensured drug release in the stomach and upper part of the gastrointestinal tract. Studies on bilayer floating polymeric tablets of hydroxyl propyl methyl cellulose (HPMC) containing metoprolol tartrate as a model drug with a prolonged gastric retention time were conducted by Narendra et al. ${ }^{10}$ The results suggest that total polymer content to drug ratio and polymer to polymer ratio have a significant impact on the floating time (FT) and release properties, but that the HPMC viscosity grade had no ef- fect. Jeganathan et al. studied the non-effervescent floating tablets of tramadol hydrochloride composed of polyethylene oxide (PEO) and a combination of cationic and anionic polymethacrylate polymers Eudragit ${ }^{\circledR}$ EPO (EE) and Eudragit $^{\circledR}$ L100-55 (EL) ${ }^{15}$ It was revealed that the optimized formulation is a combination of PEO and a mixture of EE and EL. Although there are numerous papers and patents concerning non-effervescent floating tablets, few of them address polyacrylates. ${ }^{10-15}$ In the present study, the authors propose an application of polyacrylic acid in combination with granulated sorbitol for preparation of tablets presumed for prolonged release of a model alkali drug. The parallel usage of 2 effects, floatation and ionic bonding of alkali molecules, is supported in the tablets by the addition of a soluble filler - sorbitol. The sorbitol gradually dissolves in the polymeric matrices, and may favor the prolonged release of the drug from the tablets in the stomach.

The aim of the study was to develop a new composition of non-effervescent floating tablets, and the evaluation of the effect of an anionic polymer - crosslinked polyacrylic acid (PA) and compressive force on the floatation properties and release characteristics of tablets containing the model alkaline drug, chlorhexidine (CHX).

\section{Material and methods}

\section{Material}

A hydrochloric acid solution with a concentration of $1 \mathrm{~mol} / \mathrm{L}$ (Stanlab, Gliwice, Poland), chlorhexidine 98\% (Sigma-Aldrich, Poznań, Poland), sorbitol P 30/60 (Roquette, Lestrem Cedex, France), Carbopol 934 NF (Lubrizol, Wickliffe, USA), and magnesium stearate (Sigma Aldrich, Poznań, Poland) were procured for use in this work.

\section{Composition and production of the tablets}

The tablets were prepared using the compounds listed in Table 1. The powders were mixed in a Turbula double cone blender (WAB, Muttenz, Switzerland), and then the tablets were made with a Fette tablet press Exacta 11 to control the compressive force in a suitable manufacturing environment with a humidity of $50 \%$ and a temperature of $22^{\circ} \mathrm{C}$. Formulations A1 and A2 were prepared without anionic polymers, and served as the control formulations.

\section{Main physical parameters: Uniformity of mass, friability, resistance to crushing, and size}

The selected physical parameters were assessed on the basis of the European Pharmacopoeia (Ph. Eur.) to evaluate the mechanical properties of the prepared tablets from batches A1, A2, B1, B2, C1, and C2. ${ }^{17}$ 
Table 1. Composition of the evaluated floating tablets

\begin{tabular}{|c|c|c|c|c|c|c|}
\hline \multirow{2}{*}{$\begin{array}{l}\text { Formulation } \\
\text { code }\end{array}$} & \multicolumn{4}{|c|}{ Components } & \multirow{2}{*}{$\begin{array}{l}\text { TW } \\
(\mathrm{g})\end{array}$} & \multirow{2}{*}{$\begin{array}{l}\mathrm{CF} \\
(\mathrm{kN})\end{array}$} \\
\hline & $\begin{array}{l}\mathrm{SL} \\
(\mathrm{g})\end{array}$ & $\begin{array}{l}\text { PA } \\
\text { (g) }\end{array}$ & $\begin{array}{l}\text { MS } \\
(\mathrm{g})\end{array}$ & $\begin{array}{l}\mathrm{CHX} \\
\text { (g) }\end{array}$ & & \\
\hline$A 1^{*}$ & 0.440 & 0.000 & 0.005 & 0.005 & 0.450 & 2.5 \\
\hline$A 2^{*}$ & 0.440 & 0.000 & 0.005 & 0.005 & 0.450 & 25.0 \\
\hline B1 & 0.417 & 0.023 & 0.005 & 0.005 & 0.450 & 2.5 \\
\hline B2 & 0.417 & 0.023 & 0.005 & 0.005 & 0.450 & 25.0 \\
\hline C1 & 0.395 & 0.045 & 0.005 & 0.005 & 0.450 & 2.5 \\
\hline$C 2$ & 0.395 & 0.045 & 0.005 & 0.005 & 0.450 & 25.0 \\
\hline
\end{tabular}

SL - sorbitol; PA - crosslinked polyacrylic acid; MS - magnesium stearate; CHX - chlorhexidine; TW - total weight; CF - compression force; * control formulations.

The uniformity of mass of the tablets was assessed on 20 tablets taken at random and weighed individually. The average mass, was determined, and the respective percentage deviation was calculated. The friability, mass, and size were evaluated according to the Ph. Eur. ${ }^{18}$ The friability was assessed on 12 tablets from every batch in a tablet friability apparatus compatible with the $\mathrm{Ph}$. Eur. The rotational speed was set to $100 \mathrm{rpm}$. Tablet resistance to crushing was also performed in accordance with the respective Ph. Eur. monograph using a system with a precision of $1 \mathrm{~N}$. The measurements were performed on 10 tablets, placed with the tablet plane parallel to the jaws of the device. ${ }^{19}$ The size of the tablets produced was assessed using a Mitutoyo (Kawasaki, Japan) digital micrometer with a precision of $0.001 \mathrm{~mm}$.

\section{Scanning electron microscopy}

The cross-sections of formulations A1-C2 were imaged using scanning electron microscopy. A LEO 1525 (Zeiss GmbH, Jena, Germany) was used for the microphotographs with an extra high tension (EHT) of $10.00 \mathrm{kV}$.

\section{Matrix integrity and water content of the evaluated tablets}

The matrix integrity of the tablets was monitored visually and recorded on macrophotographs. After $24 \mathrm{~h}$, the height and diameter of the B1, B2, C1, and C2 tablets were assessed. Then, the tablets were removed from the solution, excess water was removed with a paper towel, and the tablets were weighed before being dried and weighed again.

\section{Evaluation of floatation ability}

The floatation ability was evaluated via measurements of the floating lag time (FLT) and floatation duration (floating time, FT). FLT was assessed as the time between the introduction of the tablet into the hydrochloric acid solution and the buoyancy in the solution. FT was measured as the time that the dosage form constantly remained on the surface of the medium.

\section{Release studies}

Release studies were performed in vitro, using the Ph. Eur.-compliant Symphony 7100 type-2 paddle apparatus. ${ }^{20}$ The kinetics of $\mathrm{CHX}$ release from the individual tablets were determined at $37^{\circ} \mathrm{C}$ in a volume of $1000 \mathrm{~mL}$ of the hydrochloric acid solution with a $\mathrm{pH}=1$. The rotational speed was set to $50 \mathrm{rpm}$. The experiment was conducted for $2 \mathrm{~h}$. Samples of the solution with the released API for tablets A1 and A 2 were taken every 2 min during the first $10 \mathrm{~min}$, and every $10 \mathrm{~min}$ thereafter. In the case of tablets B1, B2, C1, and C2, $3 \mathrm{~mL}$ samples of the fluid were extracted every $10 \mathrm{~min}\left(1^{\text {st }}\right.$ hour $)$, and every $20 \mathrm{~min}$ ( $2^{\text {nd }}$ hour). The further stages of release were estimated from kinetic calculations. The amount of the released substance was determined using a UV-VIS T60 spectrophotometer (PG Instruments, Cincinnati, USA) interfaced with a PC to record the data, according to previously performed spectrophotometrical studies of $\mathrm{CHX} .^{21}$

\section{Kinetic calculations and statistical methods}

The in vitro release data was fitted to various kinetic models including: zero-order, first-order, KorsmeyerPeppas, Hixon-Crowell, and Higuchi models. ${ }^{22-24}$ Based on the obtained release equations, $\mathrm{t}_{0.5}$ of the process was calculated for all formulations. The kinetic parameters, determination coefficient R2 and the probability p of making a type I error were calculated. Curvilinear regression and ANOVA tests were performed using STATISTICA v. 10 software. ${ }^{25}$ The descriptive data is presented as arithmetic averages with respective standard deviations.

\section{Results}

\section{Main physical parameters: Mass distribution, hardness, friability, and size}

The average mass of the tablets was 449.5-451.0 mg. No more than 2 of the individual tablet masses deviated from the average mass by more than $5 \%$, and none deviated by more than $10 \%$. The friability did not exceed $1 \%$ for all the evaluated samples. The hardness of the tablets obtained was $85-322 \mathrm{~N}$ for the evaluated batches A1-C1, whereas for the batch $\mathrm{C} 2$, the hardness was greater than $350 \mathrm{~N}$. The diameter of the tablets produced was 9.969-10.019 $\mathrm{mm}$, whereas the thickness of the evaluated tablets was $4.152 \pm 0.007 \mathrm{~mm}, 3.007 \pm 0.031 \mathrm{~mm}$, 
$5.02 \pm 0.012 \mathrm{~mm}, 4.089 \pm 0.012 \mathrm{~mm}, 4.706 \pm 0.048 \mathrm{~mm}$, and $4.169 \pm 0.008 \mathrm{~mm}$, for $\mathrm{A} 1, \mathrm{~A} 2, \mathrm{~B} 1, \mathrm{~B} 2, \mathrm{C} 1$, and $\mathrm{C} 2$, respectively.

\section{Matrix integrity and water content}

Images of the cross-sections of the tablets obtained via scanning electron microscopy are presented in Fig. 1.

The mean initial mass $\left(\mathrm{M}_{0}\right)$ and volume $\left(\mathrm{V}_{\mathrm{T} 0}\right)$ of the assessed tablets, the volume of the wet tablets after $24 \mathrm{~h}$ of incubation in an acceptor fluid $\left(\mathrm{V}_{\mathrm{T} 24}\right)$, the mean vol- ume of water absorbed by the tablets over $24 \mathrm{~h}\left(\mathrm{~V}_{\mathrm{W} 24}\right)$, and the mean mass of the dry residue of the tablets after 21 days $\left(M_{21}\right)$ were gathered and are presented in Table 2 . The volume of the tablets containing the polymer increased from 2.2 times for formulation B1 to 2.9 times for formulation $\mathrm{C} 2$.

Furthermore, the tablets formed with a compressive force of $25 \mathrm{kN}$ (B2 and C2) increased in volume 2.4 and 2.9 times, respectively, whereas the volume of formulations $\mathrm{B} 1$ and $\mathrm{C} 1$ formed with 10 times less compressive force increased 2.2 and 2.6 times, respectively.
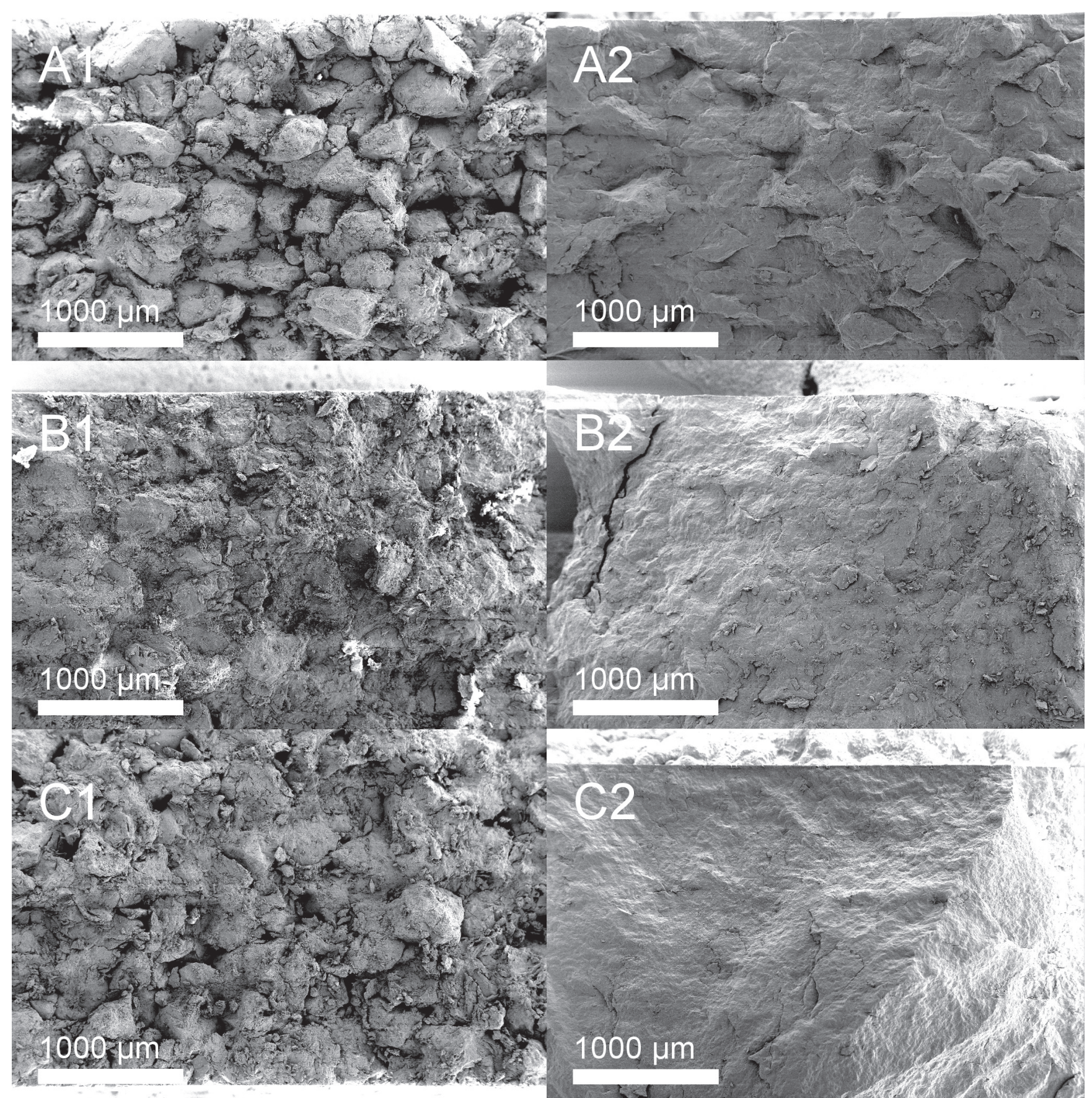

Fig. 1. Microphotographs obtained from SEM studies

The bar represents $1000 \mu \mathrm{m}$; the left column represents tablets formed with a $2.5 \mathrm{kN}$ compressive force (A1, B1, and C1), whereas the right column shows tablets formed with a compressive force of $25 \mathrm{kN}(\mathrm{A2}, \mathrm{B} 2$, and $\mathrm{C} 2)$. 
Table 2. Water intake of the assessed tablets after $24 \mathrm{~h}$ and dry residue of the tablets after 21 days of desiccation

\begin{tabular}{|c|c|c|c|c|c|c|c|}
\hline \multicolumn{2}{|c|}{ Formulation code } & \multirow{2}{*}{$\mathrm{A} 1$} & \multirow{2}{*}{$\mathrm{A} 2$} & \multirow{2}{*}{$\mathrm{B} 1$} & \multirow{2}{*}{ B2 } & \multirow{2}{*}{$\mathrm{C} 1$} & \multirow{2}{*}{$\mathrm{C} 2$} \\
\hline parameter & unit & & & & & & \\
\hline$M_{0}$ & \multirow{2}{*}{$(\mathrm{mg})$} & 450 & 450 & 450 & 450 & 450 & 450 \\
\hline$M_{21}$ & & - & - & 30.0 & 24.2 & 50.4 & 49.6 \\
\hline$V_{\text {T0 }}$ & \multirow{3}{*}{$\left(\mathrm{mm}^{3}\right)$} & 392.5 & 314.0 & 392.5 & 314.0 & 392.5 & 314.0 \\
\hline$V_{\text {T24 }}$ & & - & - & 870 & 754 & 1010 & 913 \\
\hline$V_{W 24}$ & & - & - & 564 & 496 & 951 & 855 \\
\hline
\end{tabular}

$M_{0}$ - initial mass of the tablet; $M_{21}$ - mass of the tablet after 21 days of desiccation; $V_{\text {TO }}$ - initial mean volume of the evaluated tablets; $V_{\text {T24 }}$ - mean volume of the wet tablets after $24 \mathrm{~h}$ of incubation in an acceptor fluid; $V_{\text {w24 }}$ - mean volume of water absorbed by the tablets after $24 \mathrm{~h}$ of incubation in an acceptor fluid.

\section{Floating characteristics}

The tablets swelled rapidly in the radial and axial dimensions during the in vitro study. Consequently, the density of the tablets decreased, and the tablets floated. The floatation properties of all tablet types are collected and presented in Table 3.

Table 3. Floating properties of the evaluated tablets

\begin{tabular}{|l|c|c|c|c|c|c|}
$\begin{array}{l}\text { Formulation } \\
\text { code }\end{array}$ & A1 & A2 & B1 & B2 & C1 & C2 \\
\hline FLT (min) & 15 & 31 & 61 & 89 & 80 & 105 \\
\hline FT (h) & $*$ & $* *$ & $>24 h$ & $<24 h$ & $>24 h$ & $<24 h$ \\
\hline $\begin{array}{l}\text { Observation } \\
\text { after } 24 \mathrm{~h}\end{array}$ & & $* * *$ & FS & B & FS & B \\
\hline
\end{tabular}

FT - floating time; FLT - floating lag time; * dissolved completely after 22 min; ** dissolved completely after 43 min; *** white film on the surface of the fluid; FS - floating on the fluid surface; B - on the bottom of the vessel.
Formulations A1 and A2 dissolved in the acceptor medium. Tablet A1 lifted and floated on the surface of the solution after approximately $15 \mathrm{~min}$. However, after the next $7 \mathrm{~min}$, it dissolved completely. Tablet A2 floated on the surface of the fluid after $31 \mathrm{~min}$ and gradually dissolved. Both A1 and A2 left a white film of magnesium stearate as shown in Fig. 2A.

The tablets containing the polymer (B1, B2, C1, and C2 - Fig. 2) did not dissolve and floated on the surface of the solution. Tablets B1 and C1, formed with a compressive force of approximately $2.5 \mathrm{kN}$, floated on the surface after $61 \mathrm{~min}$ and $80 \mathrm{~min}$, respectively. Tablets B2 and $\mathrm{C} 2$, which were formed with a compressive force of $25 \mathrm{kN}$, appeared on the surface of the solution after $89 \mathrm{~min}$ and 105 min, respectively. Tablets B1 and C1 floated on the surface of the fluid for over $24 \mathrm{~h}$, whereas tablets $\mathrm{B} 2$ and $\mathrm{C} 2$ sank to the bottom of the vessel. The FLT and FT were determined for the tablets, as shown in Table 3.

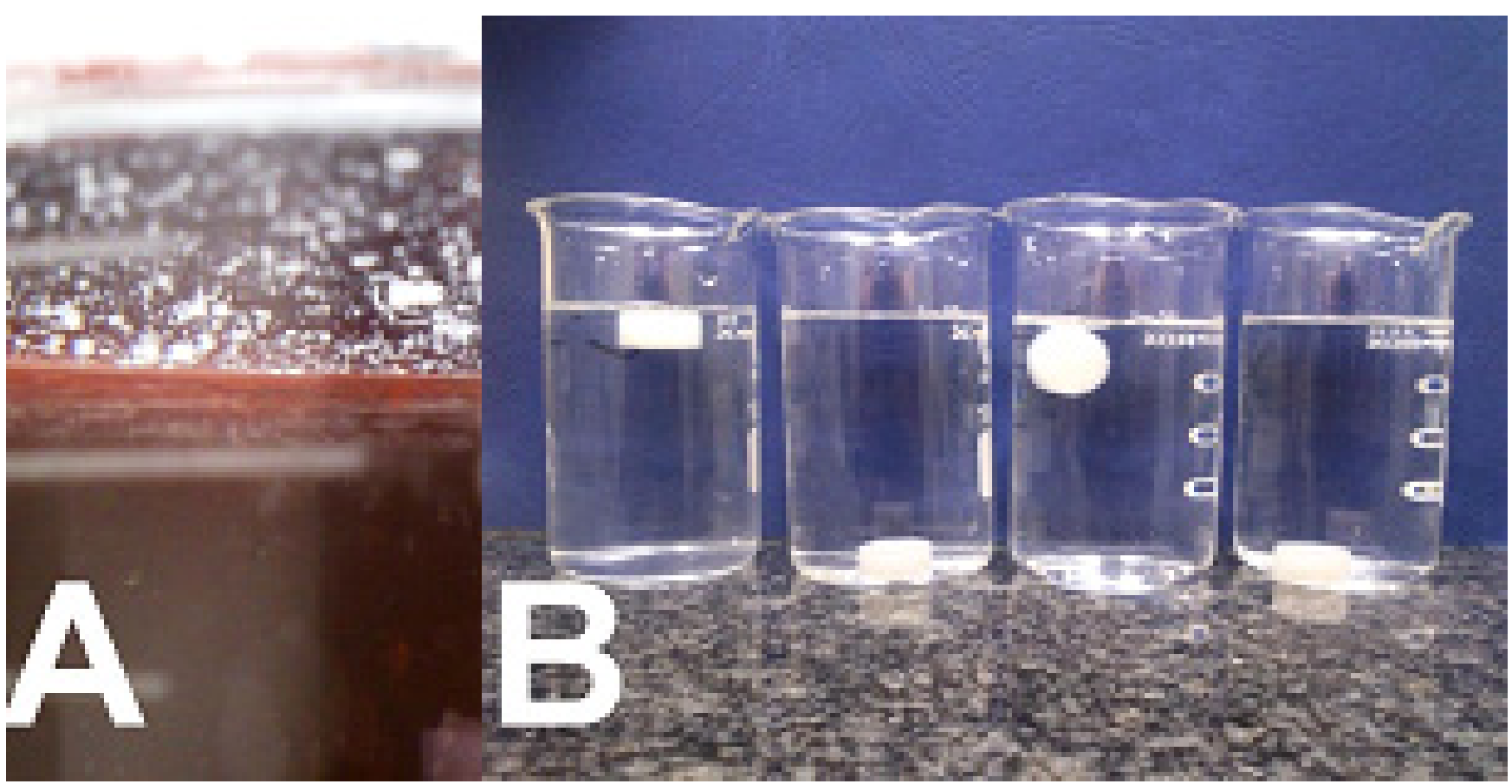

Fig. 2. The appearance of the tablets after $24 \mathrm{~h}$ of incubation in $0.1 \mathrm{~mol} / \mathrm{L}$ hydrochloric acid

$A$ - the remains of the dissolved $A 1 ; B-B 1, B 2, C 1$, and C2 formulations, from left to right, respectively. 


\section{In vitro drug release kinetics study}

The dissolution profiles of $\mathrm{CHX}$ obtained from the formulations studied are presented in Fig. 3.

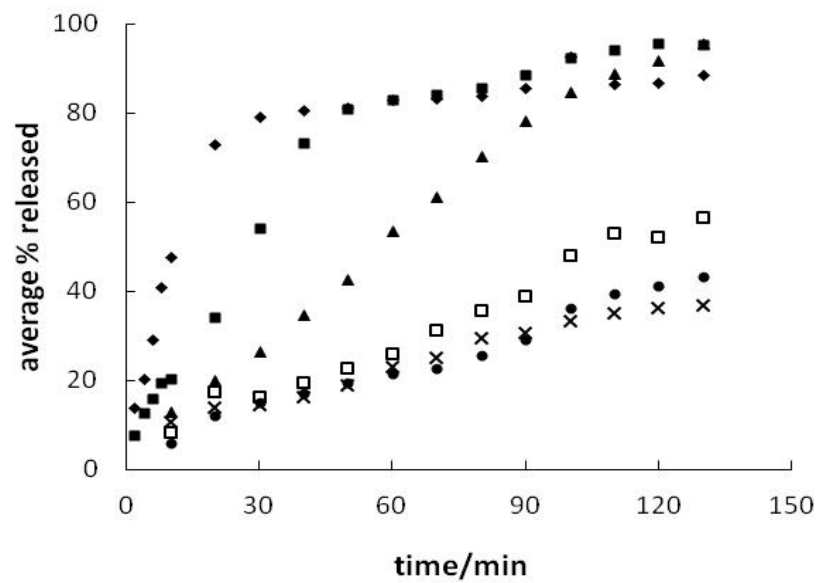

Fig. 3. The in vitro release curves of $\mathrm{CHX}$ from formulations A1 ( $), A 2(\mathbf{\bullet})$

$\mathrm{B} 1(\mathbf{\Delta}), \mathrm{B} 2(\times), \mathrm{C} 1(\square)$, and C2 (•)

Table 4. Kinetics of the in vitro drug release for the evaluated formulations and fitted to selected models

\begin{tabular}{|c|c|c|c|c|c|c|c|}
\hline \multirow{2}{*}{ M } & \multirow{2}{*}{$P$} & \multicolumn{6}{|c|}{ Formulation code } \\
\hline & & $\mathrm{A} 1$ & $\mathrm{~A} 2$ & B1 & B2 & $\mathrm{C} 1$ & $\mathrm{C} 2$ \\
\hline \multirow{3}{*}{$\mathrm{ZO}$} & $\begin{array}{l}\mathrm{K}_{0} \times 10^{3} \\
\left(\mathrm{~min}^{-1}\right)\end{array}$ & $\begin{array}{l}11.1 \\
\pm 1.3\end{array}$ & $\begin{array}{l}10.9 \\
\pm 0.9\end{array}$ & $\begin{array}{c}6.6 \\
\pm 0.2\end{array}$ & $\begin{array}{l}3.3 \\
\pm 0.1\end{array}$ & $\begin{array}{l}4.4 \\
\pm 0.1\end{array}$ & $\begin{array}{l}3.4 \\
\pm 0.1\end{array}$ \\
\hline & $R^{2}$ & 0.8233 & 0.9161 & 0.9933 & 0.9828 & 0.9952 & 0.9889 \\
\hline & $p$ & $\begin{array}{c}3.3 \\
\times 10^{-7} \\
\end{array}$ & $\begin{array}{r}4.1 \\
\times 10^{-9} \\
\end{array}$ & $\begin{array}{c}1.7 \\
\times 10^{-13}\end{array}$ & $\begin{aligned} & 2.9 \\
& \times 10^{-11}\end{aligned}$ & $\begin{aligned} & 2.6 \\
& \times 10^{-14}\end{aligned}$ & $\begin{array}{c}2.6 \\
\times 10^{-12}\end{array}$ \\
\hline \multirow{3}{*}{$\mathrm{FO}$} & $\begin{array}{l}\mathrm{K}_{1} \times 10^{3} \\
\left(\min ^{-1}\right)\end{array}$ & $\begin{array}{l}56.2 \\
\pm 3.5\end{array}$ & $\begin{array}{l}42.7 \\
\pm 4.4\end{array}$ & $\begin{array}{l}11.1 \\
\pm 0.3\end{array}$ & $\begin{array}{l}3.9 \\
\pm 0.1\end{array}$ & $\begin{array}{l}5.9 \\
\pm 0.1\end{array}$ & $\begin{array}{l}4.1 \\
\pm 0.1\end{array}$ \\
\hline & $R^{2}$ & 0.9599 & 0.8715 & 0.9939 & 0.9912 & 0.9938 & 0.9909 \\
\hline & $p$ & $\begin{array}{c}1.6 \\
\times 10^{-8}\end{array}$ & $\begin{array}{c}2.4 \\
\times 10^{-7}\end{array}$ & $\begin{array}{c}9.4 \\
\times 10^{-14}\end{array}$ & $\begin{array}{c}7.2 \\
\times 10^{-13}\end{array}$ & $\begin{array}{c}1.0 \\
\times 10^{-13}\end{array}$ & $\begin{array}{c}8.9 \\
\times 10^{-13}\end{array}$ \\
\hline \multirow{4}{*}{ KP } & $\begin{array}{l}\mathrm{K}_{\mathrm{KP}} \times 10^{2} \\
\left(\min ^{-n}\right)\end{array}$ & $\begin{array}{l}20.2 \\
\pm 2.6\end{array}$ & $\begin{array}{l}8.7 \\
\pm 0.7\end{array}$ & $\begin{array}{c}1.6 \\
\pm 0.2\end{array}$ & $\begin{array}{l}1.7 \\
\pm 0.1\end{array}$ & $\begin{array}{c}1.7 \\
\pm 0.3\end{array}$ & $\begin{array}{l}1.3 \\
\pm 0.2\end{array}$ \\
\hline & $n$ & $\begin{array}{l}0.37 \\
\pm 0.03\end{array}$ & $\begin{array}{l}0.54 \\
\pm 0.02\end{array}$ & $\begin{array}{c}0.81 \\
\pm 0.03\end{array}$ & $\begin{array}{l}0.64 \\
\pm 0.02\end{array}$ & $\begin{array}{c}0.69 \\
\pm 0.04\end{array}$ & $\begin{array}{l}0.70 \\
\pm 0.03\end{array}$ \\
\hline & $R^{2}$ & 0.8842 & 0.9738 & 0.9880 & 0.9896 & 0.9599 & 0.9781 \\
\hline & $p$ & $\begin{array}{c}2.03 \\
\times 10^{-8} \\
\end{array}$ & $\begin{array}{c}1.81 \\
\times 10^{-12}\end{array}$ & $\begin{array}{c}6.35 \\
\times 10^{-12} \\
\end{array}$ & $\begin{array}{c}2.87 \\
\times 10^{-12}\end{array}$ & $\begin{array}{l}4.93 \\
\times 10^{-9} \\
\end{array}$ & $\begin{array}{c}1.77 \\
\times 10^{-10}\end{array}$ \\
\hline \multirow{3}{*}{$\mathrm{HC}$} & $\begin{array}{l}\mathrm{K}_{\beta} \times 10^{3} \\
\left(\mathrm{~min}^{-1}\right)\end{array}$ & $\begin{array}{l}11.14 \\
\pm 0.5\end{array}$ & $\begin{array}{l}8.08 \\
\pm 0.45\end{array}$ & $\begin{array}{l}3.08 \\
\pm 0.04\end{array}$ & $\begin{array}{c}1.24 \\
\pm 0.04\end{array}$ & $\begin{array}{l}1.78 \\
\pm 0.03\end{array}$ & $\begin{array}{l}1.27 \\
\pm 0.03\end{array}$ \\
\hline & $R^{2}$ & 0.9662 & 0.9560 & 0.9977 & 0.9888 & 0.9961 & 0.9911 \\
\hline & $p$ & $\begin{array}{c}1.02 \\
\times 10^{-11}\end{array}$ & $\begin{array}{r}1.42 \\
\times 10^{-15}\end{array}$ & $\begin{array}{c}8.19 \\
\times 10^{-11}\end{array}$ & $\begin{array}{c}2.03 \\
\times 10^{-13}\end{array}$ & $\begin{array}{c}1.63 \\
\times 10^{-10}\end{array}$ & $\begin{array}{c}3.67 \\
\times 10^{-11}\end{array}$ \\
\hline \multirow{3}{*}{$\mathrm{H}$} & $\begin{array}{l}\mathrm{K}_{\mathrm{H}} \times 10^{2} \\
\left(\min ^{-0.5}\right)\end{array}$ & $\begin{array}{l}11.2 \\
\pm 0.6\end{array}$ & $\begin{array}{l}10.2 \\
\pm 0.3\end{array}$ & $\begin{array}{c}6.3 \\
\pm 0.3\end{array}$ & $\begin{array}{l}3.1 \\
\pm 0.1\end{array}$ & $\begin{array}{l}4.2 \\
\pm 0.2\end{array}$ & $\begin{array}{l}3.2 \\
\pm 0.1\end{array}$ \\
\hline & $R^{2}$ & 0.9551 & 0.9899 & 0.9792 & 0.9930 & 0.9765 & 0.9821 \\
\hline & $p$ & $\begin{array}{c}1.02 \\
\times 10^{-11}\end{array}$ & $\begin{array}{r}1.42 \\
\times 10^{-15}\end{array}$ & $\begin{array}{c}8.19 \\
\times 10^{-11}\end{array}$ & $\begin{array}{c}2.03 \\
\times 10^{-13}\end{array}$ & $\begin{array}{c}1.63 \\
\times 10^{-10}\end{array}$ & $\begin{array}{l}3.67 \\
\times 10^{-11}\end{array}$ \\
\hline & $\mathrm{BF}$ & $\mathrm{HC}$ & $\mathrm{H}$ & $\mathrm{HC}$ & $\mathrm{H}$ & $\mathrm{HC}$ & $\mathrm{HC}$ \\
\hline
\end{tabular}

M - model; P - parameter; ZO - zero-order; FO - first-order; KP - Korsmeyer-Peppas; HC - HixonCrowel; $\mathrm{H}$ - Higuchi; $\mathrm{K}_{0}, \mathrm{~K}_{1}, \mathrm{~K}_{\mathrm{KP}}, \mathrm{K}_{B}$, and $\mathrm{K}_{H}$ - the respective release rate constants; $\mathrm{BF}$ - best fit; $\mathrm{R}^{2}$ - determination coefficient; $\mathrm{p}$ - the probability $\mathrm{p}$ of making a type I error;

the value following the \pm symbol represents the standard deviation.
The release of CHX varied in each of the formulations assessed. The release kinetics of the $\mathrm{CHX}$ for formulations A1 and A2, which do not contain the polymer, were significantly different over the initial stage from those of formulations $\mathrm{B} 1, \mathrm{~B} 2, \mathrm{C} 1$, and $\mathrm{C} 2$. The release of the drug from formulation $\mathrm{A} 1$ was rapid over the initial phase before reaching a plateau after approx. $20 \mathrm{~min}$, whereas for formulation A2, a plateau was observed after approx. 40 min. The API release rate from formulations B1, B2, $\mathrm{C} 1$, and $\mathrm{C} 2$, containing the polymer, was much slower, and no plateau phase was observed. The results of the kinetic tests are reported in Table 4.

For example, graphs are shown of the release kinetics, evaluated using the various methods, for the B1 formulation. Fig. 4 shows plots for the first-order, KorsmeyerPeppas, Hixon-Crowell, and Higuchi models.

The half-release time values for the models presented are gathered together and presented in Table 5 .

\section{Discussion}

\section{Matrix integrity and intersection visualization}

The amount of the polymer incorporated in the formulations and the compressive force of the press affect the floating properties of the tablets being examined here. From Fig. 1, the visualization enables the tracking of the evaluated tablets in an aqueous environment. The huge granules represent the sorbitol, which was completely dissolved after the tests due to the loss of mass (Table 2: $\mathrm{M}_{0}-\mathrm{M}_{21}$ ). The residual mass of the tablet is a result of the anionic polymer, and may represent insoluble magnesium stearate and a residual part of the active substance. The visualization indicates that higher compression results in a highly compact structure which should be more resistant to water inflow. The increase in the polymer content leads to a visual homogenization of the structure at higher pressures.

When floating on the surface of the solution, tablet formulations B1, B2, C1, and C2 exhibited good matrix integrity. The increase in the tablet volume in water depends on the quantity of the polymer within the formulation, whereas the increased pressure during the tableting process decreases the volume of the tablet after incubation 

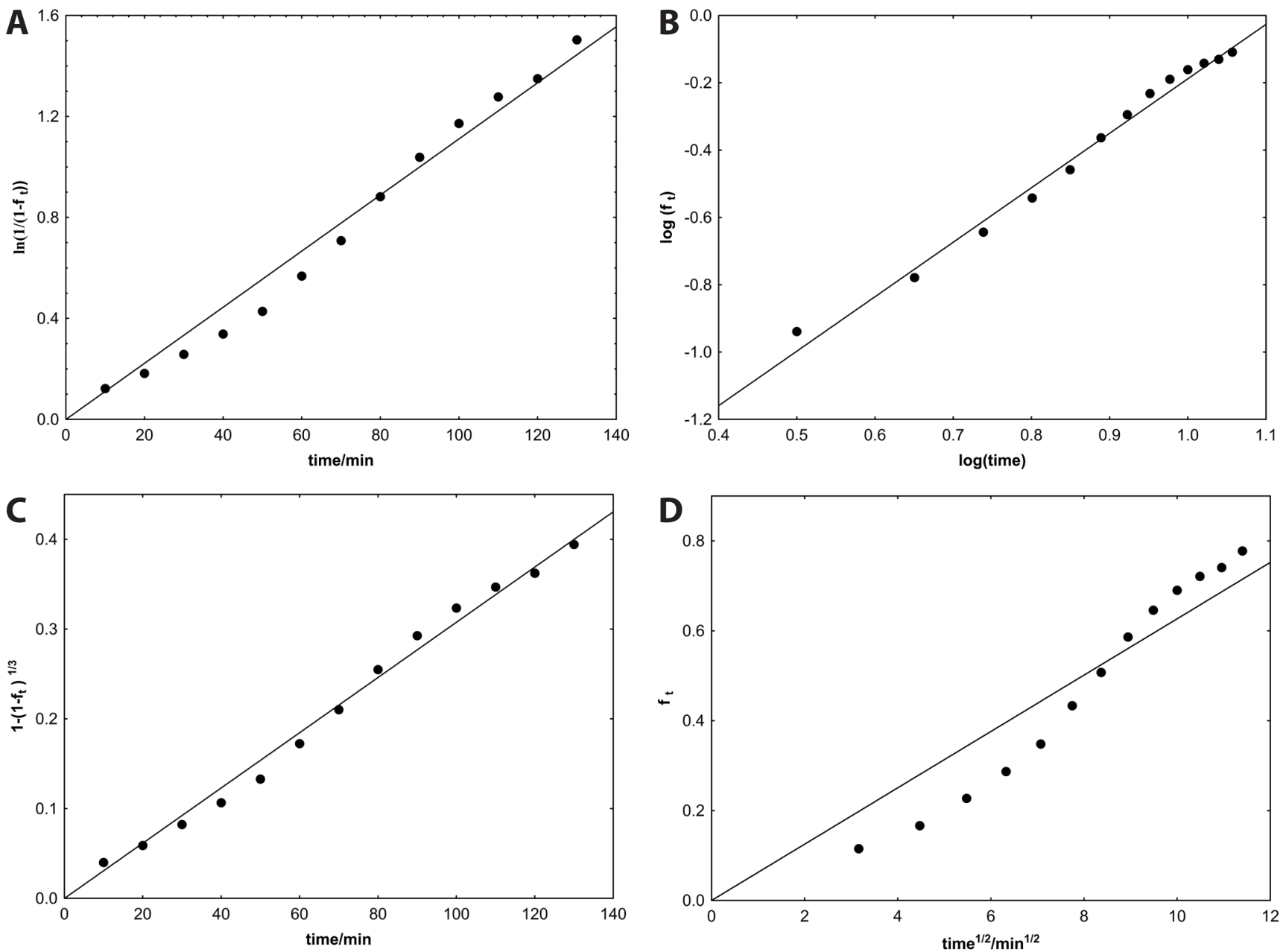

Fig. 4. Graphs of the release kinetics for the B1 formulation

A - first-order model; B - Korsmeyer-Peppas model; C - Hixon-Crowell model; D - Higuchi model.

Table 5. Half-release times for the evaluated formulations (details shown in the text)

\begin{tabular}{c|c|c|c|c|c|c|}
\multirow{2}{*}{ M } & \multicolumn{7}{|c}{ Formulation code } \\
\cline { 2 - 7 } & A1 & A2 & B1 & B2 & C1 & C2 \\
\cline { 2 - 7 } & \multicolumn{7}{|c|}{$\mathrm{t}_{0.5}(\mathrm{~min})$} \\
\hline ZO & $45 \pm 5$ & $46 \pm 4$ & $75 \pm 2$ & $152 \pm 6$ & $113 \pm 2$ & $149 \pm 5$ \\
\hline FO & $12 \pm 1$ & $16 \pm 2$ & $62 \pm 1$ & $175 \pm 5$ & $117 \pm 3$ & $169 \pm 5$ \\
\hline KP & $11 \pm 4$ & $25 \pm 4$ & $72 \pm 10$ & $202 \pm 26$ & $128 \pm 33$ & $185 \pm 34$ \\
\hline HC & $19 \pm 1$ & $26 \pm 1$ & $67 \pm 1$ & $167 \pm 5$ & $116 \pm 2$ & $162 \pm 4$ \\
\hline$H$ & $20 \pm 2$ & $24 \pm 1$ & $64 \pm 5$ & $255 \pm 12$ & $144 \pm 13$ & $249 \pm 19$ \\
\hline
\end{tabular}

$\mathrm{M}$ - model; $\mathrm{t}_{05}$ - in vitro half-release time; $\mathrm{ZO}$ - zero-order; $\mathrm{FO}$ - first-order; KP - Korsmeyer-Peppas; HC - Hixon-Crowell; $\mathrm{H}$ - Higuchi; the value after the \pm symbol represents the standard deviation; $n=5$.

in the acceptor fluid. The $M_{21}$ parameter reflects the residual amount of polymer forming in the tablets, whereas the difference between $M_{0}$ and $M_{21}$ illustrates the amount of dissolved sorbitol (Table 2). This data correlates with the initial amount of polymer and sorbitol in the formulation (Table 1).

\section{Floatation}

The tablets produced using a force of $2.5 \mathrm{kN}$ exhibited shorter FLTs than tablets produced using a force of $25 \mathrm{kN}$. Bijumol et al. revealed that an increase in the hardness of the tablets resulted in a significant increase in the FLT by $15-30 \mathrm{~min}$, which is in good agreement with the results obtained in this study. ${ }^{14}$ Furthermore, formulations made with a compression force of $2.5 \mathrm{kN}$ (B1 and C1) floated on the surface of the solution for a much longer period than tablets $\mathrm{B} 2$ and $\mathrm{C} 2$, which were formed with a compressive force of $25 \mathrm{kN}$, and exhibited an FT that was less than $24 \mathrm{~h}$. These observations are well correlated with previous results reported by Jeganathan et al. ${ }^{15}$ The tablets fabricated with the highest compressive force were found to sink in aqueous conditions, suggesting that the total tablet density may be greater than $1.0 \mathrm{mg} / \mathrm{mm}^{3}$. Otherwise, formulations $\mathrm{B} 1-\mathrm{C} 2$, which contain PA, exhibited a more controlled release profile than formulations without the polymer, such as A1 and A2, which were almost completely dissolved after 22 and $43 \mathrm{~min}$, 
respectively. It is worth noting that the FT for formulations $\mathrm{B} 1$ and $\mathrm{C} 1$ were the longest obtained in this work, and simultaneously higher than that reported in other works concerning non-effervescent floating tablets. ${ }^{11,14,15}$

The floating properties of the tablets may be ascribed to the properties of the PA, i.e., to the hydrogen bonding groups, strong anionic charges and high molecular weight. ${ }^{26} \mathrm{PA}$ resins are hydrophilic substances that are insoluble in water and swell when dispersed in water to form colloidal suspensions. When they come into contact with water, PA polymers increase their original volume and diameter. Because the $\mathrm{pKa}$ of these polymers is approximately 6.0, carboxyl groups in the main chain of the polymer may undergo ionization in an aqueous environment. The polymer swells as a result of the electrostatic repulsion between anionic groups. ${ }^{27}$ However, the acidic $\mathrm{pH}$ should hinder this process. In the present study, the polymer matrix of the tablet, with implemented alkali CHX in the acidic acceptor fluid, is penetrated by the solvent. After being placed into a solution, the dimensions of the polymer particles increase as a result of limited polymer relaxation, initially resulting in a gel formation around the tablet, which was shown as an increase in the tablet volume, as shown in Table 2 - VT24 for the B1-C2 formulations. A high compressive force during tablet formation has a negative impact on the floating properties by decreasing the free space between the polymer chains. Consequently, limited penetration of the solvent into the particles results in prolonged matrix swelling.

\section{Release study}

The diffusion coefficient $\mathrm{n}$ determined via the Korsmeyer-Peppas model was less than $0.45(0.37 \pm 0.03)$ for only the control formulation A $1 .{ }^{22}$ For the other 5 formulations, the value of the diffusion coefficient $n$ was between $0.54 \pm 0.02$ and $0.81 \pm 0.03$. These values imply that the mechanism behind the CHX release in tablets $\mathrm{B} 1$, $\mathrm{B} 2, \mathrm{C} 1$, and $\mathrm{C} 2$ is not based solely on diffusion. The value of the release exponent $\mathrm{n}$ obtained indicates a coupling of the diffusion and erosion mechanisms, which corresponds to the so-called anomalous transport or non-Fickian model. The API release is rapid over the initial stage because the drug dissolves on the surface of the tablet, and a gel layer is formed with time as a result of the hydrophilic polymer making contact with water. Other factors that affect the flotation properties of the tablets and drug release rate may include electrostatic interactions within the tablet and the environmental $\mathrm{pH}$.

Other authors examined the impact of the rate of water intake by a polymer matrix composed of Carbopol 934 $\mathrm{P}$ and verapamil hydrochloride, an alkaline drug, on the swelling of the polymer matrix. ${ }^{27}$ The results showed that the drug-to-polymer ratio had an important impact on both the interaction between the drug and the poly- mer, and on the rate of water absorption by the polymer. However, $\mathrm{pH}$ has a significant impact on the drug release rate. PA is an anionic polymer, and changes its solubility with the environmental $\mathrm{pH}$. An increase in the viscosity coefficient can be observed with the increase of $\mathrm{pH}$, according to the ionization and, consequently, the swelling of the polymer net. ${ }^{28}$ The structure of $\mathrm{CHX}$ contains $10 \mathrm{ni}-$ trogen atoms that enable bonding with the carboxyl groups in the PA. In a previous work, $\mathrm{CHX}$ with PA at a $\mathrm{pH}$ of approximately 5 formed a strong insoluble salt complex, resulting in a very weak $\mathrm{CHX}$ release, which is within the error range. ${ }^{29}$ In the current work, the $\mathrm{pH}$ value was similar to that found in the stomach, namely approx. 1 . This may slow the dissociation of PA and lead to the retarded release of $\mathrm{CHX}$ from the tablets due to the formation of a relatively low ionized polymeric matrix. Thus, a limited affinity of the cationic groups of the CHX to the negatively charged carboxyl groups may be expected. Binding of the functional groups of the polymer, and the ionic sites of $\mathrm{CHX}$ can result in the delayed release of the drug from the polymeric matrix. The formation of a complex may be responsible for longer $\mathrm{CHX}$ retention. Ionic interaction between the $\mathrm{CHX}$ and polycarboxylate containing the carboxylic groups was proposed, based on the Raman spectra obtained by Jones et al. ${ }^{30}$

The in vitro drug release data was subjected to a goodness of fit test using a linear regression analysis according to zero-order, first-order, Korsmeyer-Peppas, HixonCrowell, and Higuchi models to determine the mechanism behind the drug release. ${ }^{22-24}$ The results of this analysis are listed in Table 4. Based on the determination coefficients (R2), the best fitted models were determined. For the control formulation A1 and formulations B1, C1, and $\mathrm{C} 2$, the highest determination coefficient $\mathrm{R} 2$ was obtained for the Hixon-Crowell model, whereas formulations A2 and B2 are best described by the Higuchi model. Furthermore, the probability of making a type I error $\mathrm{p}$ is small and ranges between $1.42 \times 10-15$ and $3.3 \times 10-7$. Thus, this probability is significantly lower than the level of significance $\alpha=0.05$, which suggests a correlation between the released drug fraction and time in virtually all models. Table 5 lists the values of $t_{0.5}$ determined for all the formulations and all models of drug substance release kinetics.

The results show that, similarly to the FLT, $\mathrm{t}_{0.5}$ is the shortest for the control formulation A1 and falls between $11 \pm 4 \mathrm{~min}$ and $45 \pm 5 \mathrm{~min}$, depending on the drug substance release kinetics model. However, A1 tablets were almost completely dissolved after $22 \mathrm{~min}$. Therefore, the $t_{0.5}=45 \pm 5$ min obtained for the zero-order kinetics model shows that the model is not well fitted for this formulation. A similar phenomenon occurs for the control formulation A2. The determined $t_{0.5}$ value falls between $16 \pm 2 \mathrm{~min}$ and $46 \pm 4 \mathrm{~min}$, whereas at $43 \mathrm{~min}$, the tablets were almost completely dissolved. The $t_{0.5}=46 \pm 4$ min calculated using the zero-order kinetics model seems very unlikely. 
The longest half-release time was noted for formulations B2 and $\mathrm{C} 2$. Considering the error limits of $\mathrm{t}_{0.5}$ for these formulations in the case of all the kinetics models, the $t_{0.5}$ values obtained are similar for tablets B2 and C2. Of the tablets containing the polymer, the smallest $\mathrm{t}_{0.5}$ value falling within the range from $62 \pm 1 \mathrm{~min}$ to $75 \pm 2 \mathrm{~min}$ was noted for formulation B1. The analysis of the half-release time of the tablets floating for over $24 \mathrm{~h}$ (B1 and $\mathrm{C} 1$ ) showed that $\mathrm{t}_{0.5}$ for formulation $\mathrm{C} 1$ is longer and falls between $113 \pm 2 \mathrm{~min}$ and $144 \pm 13$ min, which suggests that $C 1$ is the optimal formulation in terms of the FT and $t_{0.5}$.

According to the in vitro data obtained, the proposed compositions may enable prolonged release of cationic drugs, e.g., some antibiotics, antihistaminic drugs, or neutralizing agents, in the cases when long and local activity of the drug in the stomach is demanded. The therapeutic target, after expanded studies, including ex vivo and in vivo research, may cover i.a. patients with chronic gastric diseases.

\section{Conclusion}

We demonstrated that tablet buoyancy is promoted by a low compressive force as the solvent particles may freely penetrate the free spaces within the tablet. This phenomenon is indirectly confirmed via SEM photographs. The FT and FLT were found to be dependent on the amount of polymer incorporated in the formulations. Introduction of the polymer into formulations B1, B2, C1, and C2 provides the desired floating ability and prolonged drug release. $\mathrm{C} 1$ is determined to be the optimal formulation. The results of the current study indicate that PA offers a good control over the release of $\mathrm{CHX}$ from the tablets and can be suggested for therapies that require prolonged treatment covering a daily time period.

\section{References}

1. Kagan L, Hoffman A. Systems for region selective drug delivery in the GI tract: Biopharmaceutical considerations. Expert Opin Drug Deliv. 2008;5:681-692.

2. Sood A, Panchagnula R. Design of controlled release delivery systems using a modified pharmacokinetic approach: A case study for drugs having a short elimination half-life and a narrow therapeutic index. Int J Pharm. 2003;261(1-2):27-41.

3. Klausner EA, Eyal S, Lavy E, Friedman M, Hoffman A. Novel levodopa gastroretentive dosage form: In vivo evaluation in dogs. $J$ Control Release. 2003;88:117-126.

4. O'Reilly S, Wilson CG, Hardy JG. The influence of food on the gastric emptying of multiparticulate dosage forms. Int J Pharm. 1987;34:213-216.

5. Sangekar S, Vadino WA, Chaudry I, Parr A, Beihn R, Digenis G. Evaluation of effect of food and specific gravity of tablets on gastric retention time. Int J Pharm. 1987;35(3):187-191.

6. Khosla R, Feely LC, Davis SS. Gastrointestinal transit of non-disintegrating tablets in fed subjects. Int J Pharm. 1989;53(2):107-117.

7. Natarajan R, Kaveri N, Rajndran NN. Formulation and evaluation of aceclofenac gastro retentive drug delivery system. Res J Pharm Biol Chem Sci. 2011;2(1):765-771.

8. Rangapriya M, Manigandanm V, Natarajan R, Mohankumar K. Formulation and evaluation of floating tablets of pioglitazone hydrochloride. Int J Pharm Chem Sci. 2012;1(3):1048-1054.
9. Baru CR, Vidyadhara S, Rao KVR, Prakash KV, Umashankar B. Formulation and evaluation of ibruprofen floating tablets. Int J Pharm Chem Biol Sci. 2012;2(4):472-481.

10. Narendra C, Srinath MS, Babu G. Optimization of bilayer floating tablet containing metoprolol tartrate as a model drug for gastric retention. AAPS Pharm Sci Tech. 2006;7(2):E34.

11. Sauzet C, Claeys-Bruno $M$, Nicolas $M$, Kister J, Piccerelle $P$, Prinderre P. An innovative floating gastro retentive dosage system: Formulation and in vitro evaluation. Int J Pharm. 2009;378:23-29.

12. Rani SB, Hari VBN, Reddy BA, Punitha S, Devi P, Rajamanickam V. The recent developments on gastric floating drug delivery systems: An overveiw. Int J Pharm Tech Res. 2010;2(1):524-534.

13. Jamil F, Kumar S, Sharma S, Vishvakarma P, Singh L. Review on stomach specific drug delivery systems: Development and evaluation. Int J Res Pharm Biomed Sci. 2011;2(4):1427-1433.

14. Bijumol C, William $\mathrm{H}$, Kurien J, Kurian T. Formulation and evaluation of floating tablets of theophylline. Hygeia J D Med. 2013;5(1):23-31.

15. Jeganathan B, Prakya V. Preparation and evaluation of floating extended release matrix tablet using combination of polymethacrylates and polyethylene oxide polymers. Int J Pharm Pharm Sci. 2014;6(8):584-592.

16. Russell TL, Beradi RR, Barmett JL, et al. Upper gastrointestinal pH in seventy-nine healthy, elderly, North American men and women. J Pharm Res. 1993;10(2):187-196.

17. Council of Europe. European Pharmacopoeia Commission. Uniformity of mass of single-dose preparations (Chapter 2.9.5.). In: European Pharmacopoeia. $6^{\text {th }}$ ed. Strasburg: Council of Europe; 2007:278.

18. Council of Europe. European Pharmacopoeia Commission. Friability of uncoated tablets, harmonised (Chapter 2.9.7.). In: European Pharmacopoeia. $6^{\text {th }}$ ed. Strasburg: Council of Europe; 2009:1500.

19. Council of Europe. European Pharmacopoeia Commission. Resistance to crushing of tablets (Chapter 2.9.8.). In: European Pharmacopoeia. $6^{\text {th }}$ ed. Strasburg: Council of Europe; 2007:279.

20. The United States Pharmacopoeial Convention, Inc. The United States Pharmacopeia $33^{\text {st }} \mathrm{ed}$. and The National Formulary $26^{\text {th }} \mathrm{ed}$. (USP-NF). Rockville, MD: USP; 2007:2161-2162.

21. MusialW, Voncina B, Pluta J, Kokol V. The study of release of chlorhexidine from preparations with modified thermosensitive poly-N-isopropylacrylamide microspheres. Sci World J. 2012;2012:1-8.

22. Korsemeyer RW, Gurny R, Doelker E, Buri P, Peppas NA. Mechanism of solute release from porous hydrophilic polymers. Int J Pharm. 1983;15:25-35.

23. Hixon AW, Crowell JH. Dependence of reaction velocity upon surface and agitation. Ind Eng Chem. 1931;23:923-931.

24. Higuchi T. Mechanism of sustained-action medication. Theoretical analysis of rate of release of solid drugs dispersed in solid matrices. J Pharm Sci. 1963;52:1145-1149.

25. StatSoft, Inc. STATISTICA (data analysis software system), v. 10. 2011. Available from www.statsoft.com.

26. Asane GS, Nirmal SA, Rasal KB, Naik AA, Mahadik MS. Polymers for mucoadhesive drug delivery system: A current status. Drug Dev Ind Pharm. 2008;34:1246-1266.

27. Elkheshen SA. Interaction of verapamil hydrochloride with carbopol 934P and its effect on the release rate of the drug and the water uptake of the polymer matrix. Drug Develop Ind Pharm. 2001;27(9):925-934.

28. Bonacucina G, Martelli S, Palmieri GF. Rheological, mucoadhesive and release properties of carbopol gels in hydrophilic cosolvents. Int J Pharm. 2004;282:115-130.

29. Musial W, Kokol V, Voncina B. Deposition and release of chlorhexidine from non-ionic and anionic polymer matrices. Chem Pap. 2010;64(3):346-353.

30. Jones DS, Brown AF, Woolfson AD, Dennis AC, Matchett LJ. Examination of the physical state of chlorhexidine within viscoelastic, bioadhesive semisolids using Raman spectroscopy. J Pharm Sci. 2000;89(5):563-571. 